\title{
SEMINÁRIO NACIONAL SOBRE MEDIDAS EDUCACIONAIS: temas para discussão
}

NICIA M. BESSA*

Ao dar inf́cio aos trabalhos do Seminário Nacional Sobre Medidas Educacionais, apoiado e promovido pelo INEP, cabe-me agradecer as presenças dos colegas e dos especialistas que se dispuseram a trazer as contribuições de seus conhecimentos, de suas experiências. Quero agradecer também as palavras generosas de Divonzir A. Gusso. Na realidade, o que me coube foi apenas expressar as questőes e as preocupaçóes que vêm sendo objeto de reflexão e de estudos por todos que estão aqui presentes. Aquelas palavras se dirigem a todos aqui presentes. É de justiça atribuir a cada um todas as referências feitas pelo Divonzir. Em segundo lugar, ele também expôs, com profundidade, numa análise aqui feita, os problemas que afligem a educação brasileira. Cabe-me, então, trazer aqui alguns comentários e esclarecimentos sobre os trabalhos que nós vamos fazer e que interessam ao INEP.

Nestes dois dias do Seminário, o trabalho será direcionado no sentido de oferecer subsídios a açőes que o INEP pretende desenvolver. Estas ações são as seguintes:

a) conceber e implantar um sistema de avaliả̧̧ão da educação de $1^{2}$ e $2^{2}$ graus. A natureza deste sistema já foi amplamente explicada pelo Divonzir;

- Professora da Pontificia Universidade Catolles do Rio de Janeiro, (PUC-RJ). 
b) em segundo lugar, desenvolver instrumentos de aferição do desempenho escolar de alunos de $1^{2}$ e $2^{2}$ graus;

c) por último, estimular a implantaçăo de centros de pesquisa e de formação de pessoal especializado em medidas educacionais. Também a natureza destes centros foi focalizada aqui, pelo Divonzir.

O que se pretende, portanto, é que os especialistas presentes produzam cinco documentos que sirvam de base e se incorporem às discussões que, conforme se espera, virăo a ampliar o espectro das questões aqui focalizadas. Trata-se, pois, de discutir questões ligadas à medida do desempenho do aluno de primeiro e segundo graus, com vista à estruturaçăo de um sistema de aferiçăo e de avaliaçäo do sistema educacional.

Neste momento, as questōes de interesse fundamental sẫo as questőes metodológicas. Além disto, trata-se também de conceber um sistema que seja apoiado pela pesquisa e pelo trabalho de centros especializados em medidas educacionais. Com este propósito, nossos trabalhos começaräo pela apresentação de cinco pesquisas que representam experiências realizadas por iniciativa do MEC, da Fundação Carlos Chagas e da Universidade Federal de Pernambuco.

Trata-se de estudos de amplitudes diversas realizados por entidades que têm diferentes relações de poder face ao Sistema Escolar - e esta é uma das questões que podem afetar a implantação de um sistema de avaliação.

A exigüidade do tempo disponível, devo dizer, limitou o número de pesquisas a serem aqui apresentadas. Entretanto, estou certa de que os estudos, as experiências, as pesquisas, que cada um dos participantes tem realizado, enriquecerão os documentos produzidos no Seminário.

Devo também explicar a questāo dos temas escolhidos para discussăo aqui.

Em primeiro lugar, entre os temas que não serão debatidos estão muitos dos mais importantes com relação a bases conceituais e estatísticas da teoria das medidas educacionais. Por exemplo: conceitos de validade e fidedignidade, modelos estatísticos etc.

A razão da não inclusão destes temas 6 a seguinte: nós precisamos esclarecer algumas questőes básicas das quais dependem as demais. Além disto, o INEP tem a proposta de desenvolver açōes (como a estimulação dos estudos sobre medidas educacionais) e essas açōes requerem decisōes a serem tomadas em curto prazo. Outras discussões em outros encontros poderăo focalizar maior diversidade de temas, inclusive sugeridos pelos participantes do Seminário.

Eu gostaria de comentar, também, que na literatura dos últimos cinco anos, sobre perspectivas para o desenvolvimento de medidas educacionais e de sistemas de aferição do desempenho escolar, percebe-se a influência marcante de duas vertentes de pesquisas: uma, a da psicologia cognitiva e, outra, da informática na educaçăo.

No contexto de diferentes teorias psicológicas da cogniçăo, a aprendizagem é concebida como um processo de aquisiçăo do conhecimento. Aquisiçâa 
do conhecimento em que o aprendiz é ativo, seleciona e organiza estímulos, usa estratégias diversas.

Aquisição dos conhecimentos em que estão envolvidos processos metacognitivos, como levantamentos do próprio conhecimento anterior ou de recursos disponíveis. estes processos săo os que permitem a orientação das açōes para os objetivos do próprio aprendiz.

Aquisição do conhecimento entendida como um processo cumulativo em que o conhecimento anteriormente adquirido tem um papel essencial na interpretaçåo de novas informações que assim adquirem um sentido próprio para 0 aprendiz.

Um dos reflexos dessa concepção de aprendizagem pode ser identificado na procura de métodos para detectar e explicar diferenças individuais no desempenho escolar, em termos de diferenças na formação de conceitos, de juízos, diferenças na tomada de decisões, ou na memorização, por exemplo. Outro reflexo transparece nas tentativas de desenvolver medidas para detectar diferenças entre momentos sucessivos pelos quais o indivíduo passa na aquisição do conbecimento.

Tais preocupaçōes se ligam aos temas números 1 e 2 propostos em nosso programa para discussões: se o sujeito é ativo na aprendizagem, se o sujeito gera as próprias respostas para as situaçóes que se lhe apresentam, como melhor aferir o seu desempenho?

Como detectar momentos sucessivos no processo em que o sujeito interage com o ambiente e constrói as próprias respostas?

A pesquisa psicológica vem, também, robustecer o reconhecimento de que a aprendizagem depende do contexto ambiental e de estados afetivos e motivacionais. De que modo, então, aferir o desempenho de alunos de nossas escolas, tendo em vista a diversidade imensa de condiçōes em que se processa a aquisição do conhecimento? Como pode a pesquisa etnográfica desvendar tais condições, para que se possa melhor compreender o sentido de diferenças no desempenho desses alunos e para que a concepção de um sistema de aferição do desempenho leve em conta que uma mesma situação de aprendizagem apresentada a alunos que se formam em contexto ambientais diversos pode ser interpretada de maneiras bastantes diferentes por uns e outros?

A crescente tendência de procurar integrar a medida educacional a esta concepção de aprendizagem reflete, pelo menos em parte, a introdução da informática na educação. Na medida em que se procura tornar mais inteligentes os "softwares"educacionais, estes programas passam a incluir situações tanto de aprendizagem como de aferição diagnóstica e contínua do desempenho. É assim que se procura tornar tais programas adaptados continuamente ao progresso individual.

A integração da medida educacional às situações de aprendizagem leva à exigência de uma conceituação e de uma teoria da aferição e da avaliaçäo diag- 
nóstica e isto é um campo aberto à pesquisa. Este é um dos problemas fundamentais a serem encarados se quisermos conceber um sistema de aferição e de avaliação educacional que contribua efetivamente para a renovação da nossa escola de $1^{\imath} \mathrm{e} 2^{2}$ graus.

Na realidade, nós temos, já neste momento, no Brasil, pesquisa educacional e de alta qualidade que nos permite fazer uma avaliação a grosso modo do sistema educacional. $O$ que se pretende com o trabalho do INEP é implantar um sistema permanente que contribua para melhorar continuamente a qualidade da educação em nossas escolas. Isto significa que se tem uma oportunidade, afinal, de integrar um sistema de aferição e avaliação ao sistema instrucional e, com isto, contribuir para alterar tanto a prática pedagogica, quanto características gerais desse sistema educacional.

Nós já sabemos que temos um sistema educacional altamente centralizado, caracterizado pela rigidez das normas, muitas das quais de âmbito nacional. Um sistema cujos objetivos convergem quase que exclusivamente para a preparação à Universidade. Um sistema que confunde conhecimento com informação. Um sistema em que a aferição do desempenho não tem função diagnóstica e, poís, não se presta para monitorar o progresso instrucional, mas serve à seleção de alunos que devem ter acesso a novas informações. Um sistema que pressupōe a ordenação lógica de disciplinas e programas por séries anuais à margem, portanto, do que conhecemos dos processos de aquisição do conhecimento por crianças, adolescentes e adultos. Um sistema que pressupōe, sem base científica, que a simples retenção do aluno na série promova o aprendizado, malgrado os efeitos negativos em relação à motivaçào e à auto-estima. Um sistema que se baseia na transmissão principalmente verbal das informações, avesso à tecnologia que oferecem os recursos de multimeios e da comunicação direta entre o aluno e o mestre, mesmo a longas distâncias, ou entre ambos e as fontes de informação através de redes de computadores.

Sabemos, também, que a prática pedagógica dificilmente pode ser alterada no contexto atual, em parte, pela própria formação dos professores e em parte devido à rigidez das normas que regem o sistema e a burocracia escolar. Reconstruir um sistema educacional em tal estado exige mais do que a introdução de um novo sistema de aferição. Mas como poderá um sistema de aferição do desempenho do aluno em nossa escola de $1^{g}$ e $2^{g}$ graus ser concebido, estruturado, implantado, de tal modo que possa contribuir para a remoção do sistema educacional, no sentido de torná-lo adequado às necessidades do país na entrada do século 21 ? Esta é uma questão fundamental que estimula as nossas discussões neste Seminário, de modo que eu queria, com estas palavras, deixar abertas as questōes, à espera de que a contribuição do Seminário seja refletir sobre elas. 


\section{MINISTÉRIO DA EDUCAÇÃO}

\section{INSTITUTO NACIONAL DE ESTUDOS E PESQUISAS EDUCACIONAIS (INEP)}

\section{PROGRAMADAS NAÇÕES UNIDAS PARA O \\ DESENVOLVIMENTO (PNUD)}

SISTEMA DE AVALIAÇÃO DA EDUCAÇÃO BÁSICA

\section{SEMINÁRIO NACIONAL}

SOBRE MEDIDAS EDUCACIONAIS

Brastlia, 24 e 25 de junho de 1992 